the nylon when the sting is removed by the bee. The venom is allowed to dry and is then scraped free with a sharp blade. 'The venom so collected is slightly contaminated with pollen grains and dust.

To collect the liquid fraction, two sheets of thin polyethylene ('Handiwrap', Dow Chemical Co.) (0.0254mm thick) are stretehed over the collection board and under the nylon parchment taffeta; the sting of the honoy bee cannot easily penetrate thicker sheets of polyethylene. The bees, when shocked, sting down through the taffeta and the two sheets of polyethylene. The venom is deposited as small droplets on the underside of the last sheet of plastic. The first shoct of polyethylene, covered with contaminants, is discarded. It is possible to collect about $2 \mathrm{~g}$ of venom from twenty colonies of bees in about $2 \mathrm{~h}$ with the original apparatus; the modified apparatus described here collects only about half that amount.

Some venom is lost between the sheets of plastic and in the nylon, but the material that is obtained is free of contaminants. To obtain the venom as a liquid, one must remove the last sheet of plastic rapidly, extract it with physiological saline solution or de-ionized water and quickfreeze the solution. Pure, dried venom can be obtained by drying the solution under aseptic conditions.

The thin sheet of polyethylene does not retain the stingers and the bees do not appear to suffer any adverse effects in the process of venom collection.

This investigation was supported by a U.S. Public Health Service predoctoral fellowship and a grant from the National Institutes of Hoalth.

\section{A. W. Benton}

Department of Entomology and Eeonomic Zoology, Rutgers University. New Brunswick, New Jersey.

R. A. Morse

Department of Entomology,

Cornell University, Ithaca, New York.

${ }^{1}$ Benton, A. W., Morse, R. A., and stewart, J. D., Science, 142, 228 (1963) Jenton, A. W., thesis, Corncll Univ, (1965).

\section{Pregnancy Failure in Laboratory Mice after Multiple Short-term Exposure to Strange Males}

As olfactorily induced pregnancy failure in recently inseminated laboratory mice has been shown to result from enforced cohabitation with a strange or alien male, following which the female would return to oestrus ${ }^{1}$. The females were exposed for a period of 12, 24, 48, or $72 \mathrm{~h}$, with maximum prognancy failure (approximately 80 per cent) occurring at the two longer periods, and about half as many failures with $12 \mathrm{~h}$ exposure $e^{2,3}$. In the aforementioned experiments, the female was continually subjected to the presence of the strange male. The purpose of the present investigation was to determine if multiple, short-term exposures of the newly inseminated female to strange males would reduce the pregnancy rate.

Our experiments were conducted with virgin albino females, 50-60 days of age, woighing approximately 25 g. and showing a perforate vaginal orifice. Opaque plastic window boxes $22 \mathrm{in}$. by $5.25 \mathrm{in}$. by $5.5 \mathrm{in}$. high with wire mesh tops were used throughout as eages. Females were paired individually with a stud male (albino) of proved fertility and examined each morning for the presence of a vaginal plug. The male was removed from the female's cage when sho showed a vaginal plug. The female remained in her home cage for $24 \mathrm{~h}$, after which she was subjected to one of four treatments, as follows: The female was $(a)$ left undisturbed in her cage for 7 days (control); (b) placed for 7 days in a cage containing a resident wild male house mouse; (c) transferred to a cage containing a resident wild male house mouse for three 15 min periods per day for 4 days; $(d)$ transferred to an empty cage for periods identical to $(c)$. Each treatment consisted of fifty animals. Females were killed on the seventh dav in order to determine whether or not they were pregnant. All treatments were tested for significance by $\chi^{2}$ anlalysis. Wild males were used as strange males, in part to prove thoir capacity to block pregnancies and in part to provide as wide a spectrum of odours as possible, thus assuring maximum pregnancy failure.

For the fifty females in treatment $a$ there were fortyfive pregnancies (90 per cent), while those in treatment $b$ had only twenty-two prognancies (44 per cent). This is a significant reduction in pregnancy rate $(P<0.001)$. For the fifty females subjected to wild males for short periods (treatment $c$ ) there were twenty-five pregnancies (50 per cent). This pregnancy rate is also a significant reduction from the control $(P<0.001)$ but is not significantly different from the constant exposure to the wild males (treatment $b$ ). Of the fifty fomales exposed to empty cages (treatment $d$ ) there wero forty pregnaneies $(80$ per cent), which was a significant increase in pregnancy rats from the continuous or priodic exposure to the wild males $(P<0.001)$ but was not significantly different from the control (treatment; $a$ ).

Our data indicate that multiple short-term exposure of at recently inseminated female to a wild male will cause essentially the same degree of pregnaney failure as the continuous exposure to a wild male. The 15 min exposure may be considered a longer period of contact than might occur under natural conditions; however, we believe that the short exposure approximates more closely the degree of contact in the enviromment than continuous exposure. Since the exposure periods were 4-12 h apart, we suggest that in the natural habitat the periodic contact of a recently inseminated female with several male mice or trails containing their odours would bo adequate to induce sorne pregnancy failure, and thus would contribute toward decreased recruitment in the population. Recent investigations ${ }^{4,5}$ indicate $(\alpha)$ in two high-density natural populations, a general failure of adult fomales to become pregnant as well as an inerease in the percentage of parous. non-pregnant females in the older age classes at the time of and immediately following the peak in the population: and (b) an increase in the reproductive rate when females from confined populations were allowed to disperse into uninhabited areas.

This study was supported by an award from the National Institutes of Health.

Robert K. ChipmaN JOHN A. HoLT*

KEVIN A. Fox*

Department of Zoology,

University of Vermont.

Burlington, Vermont.

* Tational Aeronautics and Space Administration Predoctoral Trainee. 1 Bruce, H. M., Nature, 180, 159 (1959).

2 Bruce, H. M., J. Repro. Fertil., 1, 96 (1960)

s Bruce, H. M., J. Repro. Fertil., 6, 451 (1963).

1 Tearson, O. P. Ecology, 44, 540 (1963)

"Croweroft, P., and Rowe, F, P., Proc. Zool. Soc., Lomdon, 131. 357 (1958).

\section{MICROBIOLOGY}

\section{Some Observations on Staphylococcal Pigmentation}

VARIOUs substances added to nutrient agar media are known to enhance colonial pigmentation of Staphy. lococcus aureus. These include sterile cow's milk $k^{1,2}$, fermentable carbohydrate ${ }^{3}$, sodium chloride ${ }^{4}$, glycorophosphoric acid ${ }^{5}$ and glycerol monoacetate ${ }^{6}$. Not all these are equally effective, however, the most intense pigmentation being developed on milk agar and on glycerol monoacctate agar. Glycerol monoacetate agar has the additional advantage that strains of Staph. aureus growing 